\title{
Cloning and pattern of expression of trehalose-6-phosphate synthase cDNA from Catantops pinguis (Orthoptera: Catantopidae)
}

\author{
Bin TANG ${ }^{1,2}$, HuI-Zhen ZHENG ${ }^{1}$, Qi XU ${ }^{1}$, Qi ZOU ${ }^{1}$, GuANG-Jun WANG ${ }^{2}$, FAN ZHANG ${ }^{3}$, Shi-Gui WANG ${ }^{1 *}$ \\ and Ze-HuA ZHANG ${ }^{2 *}$
}

\author{
${ }^{1}$ Hangzhou Key Laboratory of Animal Adaptation and Evolution, Hangzhou Normal University, Hangzhou, Zhejiang, 310036, \\ China \\ ${ }^{2}$ State Key Laboratory for Biology of Plant Diseases and Insect Pests, Institute of Plant Protection, Chinese Academy of Agricultural \\ Sciences, Beijing, 100193, China \\ ${ }^{3}$ Institute of Plant and Environment Protection, Beijing Academy of Agriculture and Forestry Sciences, Beijing 100 097, China
}

Key words. Orthoptera, Catantopidae, Catantops pinguis, trehalose-6-phosphate synthase, cloning, sequence analysis, expression pattern

\begin{abstract}
Trehalose is not only an important disaccharide, but also a key stress resistance factor in the development of many organisms, including plants, bacteria, fungi, and insects. To study the potential function of trehalose in development and behaviour, cDNA for a trehalose-6-phosphate synthase from Catantops pinguis (CPiTPS) was cloned and sequenced. Results revealed that the CpiTPS cDNA sequence contains an open reading frame of 2430 nucleotides encoding a protein of 809 amino acids with a predicted molecular weight of $91.13 \mathrm{kDa}$ and a $\mathrm{p} I$ value of 6.25 . Northern blot and RT-PCR analyses showed that CpiTPS mRNA expression was high in the fat body and testes, ovaries, Malpighian tubules, brain, trachea, rectum, and posterior extensor of $C$. pinguis. Northern blotting revealed that CPiTPS mRNA was expressed in the fat body at different developmental stages and was present at a high level in first instar larvae and adults. The results demonstrate that CpiTPS is a key gene in C. pinguis development.
\end{abstract}

\section{INTRODUCTION}

Abiotic stress is the most important limiting constraint on crop productivity and yield, and could compromise food supply for the ever-increasing human population in the future. Organisms have evolved two different strategies to cope with abiotic stress (Avonce et al., 2006). First, some species that live in extreme environments can modify features of their metabolic capability such as optimal enzyme activity and membrane stability (Madigan \& Oren, 1999). Second, some organisms have evolved a drastically different adaptation to cope with stress when exposed to extreme conditions. They evolved biosynthetic pathways for compounds such as mannitol, sorbitol, sucrose, and trehalose, which are utilized for survival until conditions become favourable again (Yancey et al., 1982). In the case of insects, they accumulate large amounts of trehalose, a blood sugar, in extreme environments.

Trehalose ( $\alpha$-D-glucopyranosyl-1,1- $\alpha$-D-glucopyranoside) is an important disaccharide (Birch et al., 1963; Elbein, 1974; Ryu et al., 2005), which is widespread among bacteria, yeasts, fungi, nematodes, plants, insects and some other invertebrates (Crowe et al., 1984; Gadd et al., 1987; Strøm \& Kaasen, 1993; Benaroudj et al., 2001). In plants, trehalose plays a role as an anti-stress substance by protecting against drought, high salt, and low temperature (Garg et al., 2002; Elbein et al., 2003, Jang et al., 2003). It can stabilize dehydrated enzymes, proteins, and lipid membranes efficiently and protects biological structures against damage during desiccation (Fillinger et al., 2001; Garg et al., 2002; Elbein et al., 2003).

There are three main ways for organisms to synthesize trehalose in vivo (Kong et al., 2001). The first is via catalysis by trehalose synthase, as in some bacteria (Thermus aquaticus), which can convert maltose to trehalose by transglycosidation (Tsusaki et al., 1997; Kong et al., 2001). The second is via the reaction of $\beta$-glucose 1-phosphate and glucose catalyzed by trehalose-6phosphate phosphatase, as in Micrococcus varians (Kizawa et al., 1995). Many organisms have adapted the latter mechanism to synthesize trehalose via a twoenzyme system of trehalose-6-phosphate synthase (TPS) and trehalose-6-phosphate phosphatase (TPP), which requires a high-energy intermediate of glucose metabolism as a substrate (Kong et al., 2001).

In insects, trehalose is a major blood sugar. It is synthesized mainly by the fat body (an organ analogous in function to a combination of the liver and adipose tissue in vertebrates) and is released rapidly into the hemolymph and other tissues in larvae, pupae, and adults (Candy \& Kilby, 1959, 1961; Elbein, 1974; Becker et al., 1996; Tang et al., 2008). It is reported that trehalose is synthesized from glucose phosphate. Two enzymes are directly involved in this: TPS forms trehalose 6-phosphate from glucose 6-phosphate and UDP-glucose, after which TPP removes the phosphate to release trehalose into the hemolymph (Candy \& Kilby, 1959, 1961). However, molecular

\footnotetext{
* Corresponding authors; e-mails: SGW: sgwang@mail.hz.zj.cn; ZHZ: lgbcc@263.net
} 
TABLE 1. The primers for CpiTPS cDNA cloned, Northern blot, and RT-PCR.

\begin{tabular}{|c|c|c|c|c|}
\hline \multirow{2}{*}{ PCR fragment } & \multicolumn{4}{|c|}{ Primers } \\
\hline & Name & Direction $^{\mathrm{a}}$ & Type $^{b}$ & Nucleotide sequence (5'-3') \\
\hline \multirow[t]{4}{*}{ Intermediate fragments } & TPS-DF1 & $\mathrm{F}$ & $\mathrm{D}$ & TGG NNT NTG GGT NGG HTG G \\
\hline & TPS-DF2 & $\mathrm{F}$ & $\mathrm{D}$ & GCT GYA ACG VNA CBT TYT GG \\
\hline & TPS-DR1 & $\mathrm{R}$ & $\mathrm{D}$ & GCC ATW CCY TTS ARV GCC \\
\hline & TPS-DR2 & $\mathrm{R}$ & $\mathrm{D}$ & ATC YTR ATN CKT TCR CTC C \\
\hline \multirow[t]{2}{*}{ Probe } & CpiTPS-FP & $\mathrm{F}$ & G & CTG CTG GTC GAA CAC GGT GG \\
\hline & CpiTPS-RP & $\mathrm{R}$ & G & CGT CAT AGT CCA GCA GCA GG \\
\hline \multirow[t]{4}{*}{ 5'-RACE } & CpiTPS-5R1 & $\mathrm{R}$ & G & AGC AAA CAG TTC ATT CAC AC \\
\hline & CpiTPS-5R2 & $\mathrm{R}$ & G & TGC TGT TGA CTG CTC CTC CA \\
\hline & CpiTPS-5R3 & $\mathrm{R}$ & G & CTG TCT GAC CCA ATT TGC TG \\
\hline & & $\mathrm{F}$ & A & AAG CAG TGG TAT CAA CGC AGA GT \\
\hline \multirow[t]{3}{*}{ 3'-RACE } & CpiTPS-3F1 & $\mathrm{F}$ & G & CTC TGA TTG AGC AGG CAG GA \\
\hline & CpiTPS-3F2 & $\mathrm{F}$ & G & AGC TGG ATC TGC CCA CTG TG \\
\hline & CpiTPS-3F3 & $\mathrm{F}$ & G & GCA AAG CCT CCG GTA CAG TG \\
\hline
\end{tabular}

The full-length CpiTPS cDNA sequence was determined by sequencing two overlapping PCR fragments using fat body cDNA as a template. The probe primers were for Northern blot and RT-PCR experiment. ${ }^{\mathrm{a}} \mathrm{F}$ - Forward; R - Reverse; ${ }^{\mathrm{b}} \mathrm{D}$ - degenerate primer; $\mathrm{G}$ - gene specific primer; A - anchor primer.

level evidence for this is lacking. During this process, TPS and TPP both play an important role in the regulation of trehalose production for growth and development (Elbein et al., 2003; Wang et al., 2005b). Chen et al. (2002) and Chen \& Haddad (2004) report that trehalose can serve as a source of energy and accumulates dramatically in HEK-293 cells, increasing tolerance to hypoxia and anoxia and protecting cells and cellular proteins against damage.

To date, although many TPS genes have been cloned or deduced from genomic sequences, there are few such studies on insects, mainly Drosophila melanogaster (Chen et al., 2002, 2003; Chen \& Haddad, 2004). TPP and TPS genes have been cloned from plants, bacteria, and fungi, but none have been identified in mammals. In arthropods, TPS and TPP have been cloned or deduced from genomic sequences (according to GenBank) and are known to be very important for insect development; however, there are only a few studies on TPS genes and the details of protein characteristics in insects: $D$. melanogaster (Chen et al., 2002), Callinectes sapidus (Chung, 2008), Locusta migratoria (Cui et al., 2009), Helicoverpa armigera (Xu et al., 2009), and Spodoptera exigua (Tang et al., 2010). Catantops pinguis (syn. Diabolocatantops pinguis) is a worldwide pest of agriculture and is a very strong flyer which requires a lot of energy, so trehalose synthesis is important in $C$. pinguis. In the present study, TPS cDNA from $C$. pinguis was cloned (GenBank accession no. GQ389790) and the tissue distribution and pattern of expression of this gene investigated.

\section{MATERIAL AND METHODS}

C. pinguis were maintained in the laboratory over a period of 1 year. Larvae were reared at $26 \pm 1{ }^{\circ} \mathrm{C}, 65 \%$ humidity and an 14L : 10D photoperiod on a diet of wheatgrass. The developmental stages were synchronized at each moult by collecting new adult larvae. The brain, trachea, midgut, rectum, testes, ovaries, Malpighian tubules, posterior extensor, heart, body wall, and fat body of adults, and the fat body of different stages, from larvae to adults, were dissected in saline containing $0.75 \%$ $\mathrm{NaCl}$ and stored at $-80^{\circ} \mathrm{C}$ until required (Kumar et al., 2008).

\section{RNA isolation and cDNA synthesis}

Total RNA was extracted from the fat body of adult C. pinguis using the acid guanidinium thiocyanate-phenol-chloroform method (Chomczynski \& Sacchi, 1987). Fat body (100 mg) was homogenized in solution D (4 M guanidinium thiocyanate, 25 $\mathrm{mM}$ sodium citrate, $\mathrm{pH} 7,0.5 \%$ sarcosyl, $0.1 \mathrm{M}$ 2-mercaptoethanol) and placed on ice for $5 \mathrm{~min}$, and then sodium acetate and chloroform/isoamyl alcohol $(49: 1)$ were added. The mixture was centrifuged at $10,000 \times \mathrm{g}$ at $4^{\circ} \mathrm{C}$ for $20 \mathrm{~min}$. The supernatant was transferred to a new tube and isopropanol added. After centrifugation, the RNA pellet was washed with $75 \%$ ethanol and then dissolved in $\mathrm{ddH}_{2} \mathrm{O}$. A sample of $1 \mathrm{mg}$ of total RNA was reverse transcribed at $42^{\circ} \mathrm{C}$ for $1 \mathrm{~h}$ in $10 \mu \mathrm{l}$ of reaction solution containing reaction buffer, $10 \mathrm{mM}$ DTT, $0.5 \mathrm{mM}$ dNTPs, $0.5 \mu \mathrm{g}$ of oligo-dT18, and 5 unit reverse transcriptase from avian myeloblastosis virus (AMV, Takara, Dalian, China).

\section{Primer design and PCR}

Four degenerate primers (TPS-DF1, TPS-DF2, TPS-DR1, and TPS-DR2; Table 1) were designed based on the conserved amino acid sequences of known TPS forms. The first PCR reaction was performed with primers TPS-DF1 and TPS-DR1 using the following conditions: three cycles of $40 \mathrm{~s}$ at $94^{\circ} \mathrm{C}, 40 \mathrm{~s}$ at $45^{\circ} \mathrm{C}$, and $120 \mathrm{~s}$ at $72^{\circ} \mathrm{C}$, followed by 30 cycles of $40 \mathrm{~s}$ at $94^{\circ} \mathrm{C}$, $40 \mathrm{~s}$ at $48^{\circ} \mathrm{C}$, and $120 \mathrm{~s}$ at $72^{\circ} \mathrm{C}$. A second PCR was carried out using the nested primers TPS-DF2 and TPS-DR2 using the same conditions as for the first PCR (Rinehart et al., 2003; Tang et al., 2008). The PCR products were subjected to agarose electrophoresis. A strong DNA band corresponding to the expected size of approximately $1700 \mathrm{bp}$ was excised from the agarose gel and purified using a DNA gel extraction kit (Takara, Dalian, China). The PCR products were cloned into the pMD18-T vector (Takara, Dalian, China) and sequenced using the dideoxynucleotide method (Takara, Dalian, China). 


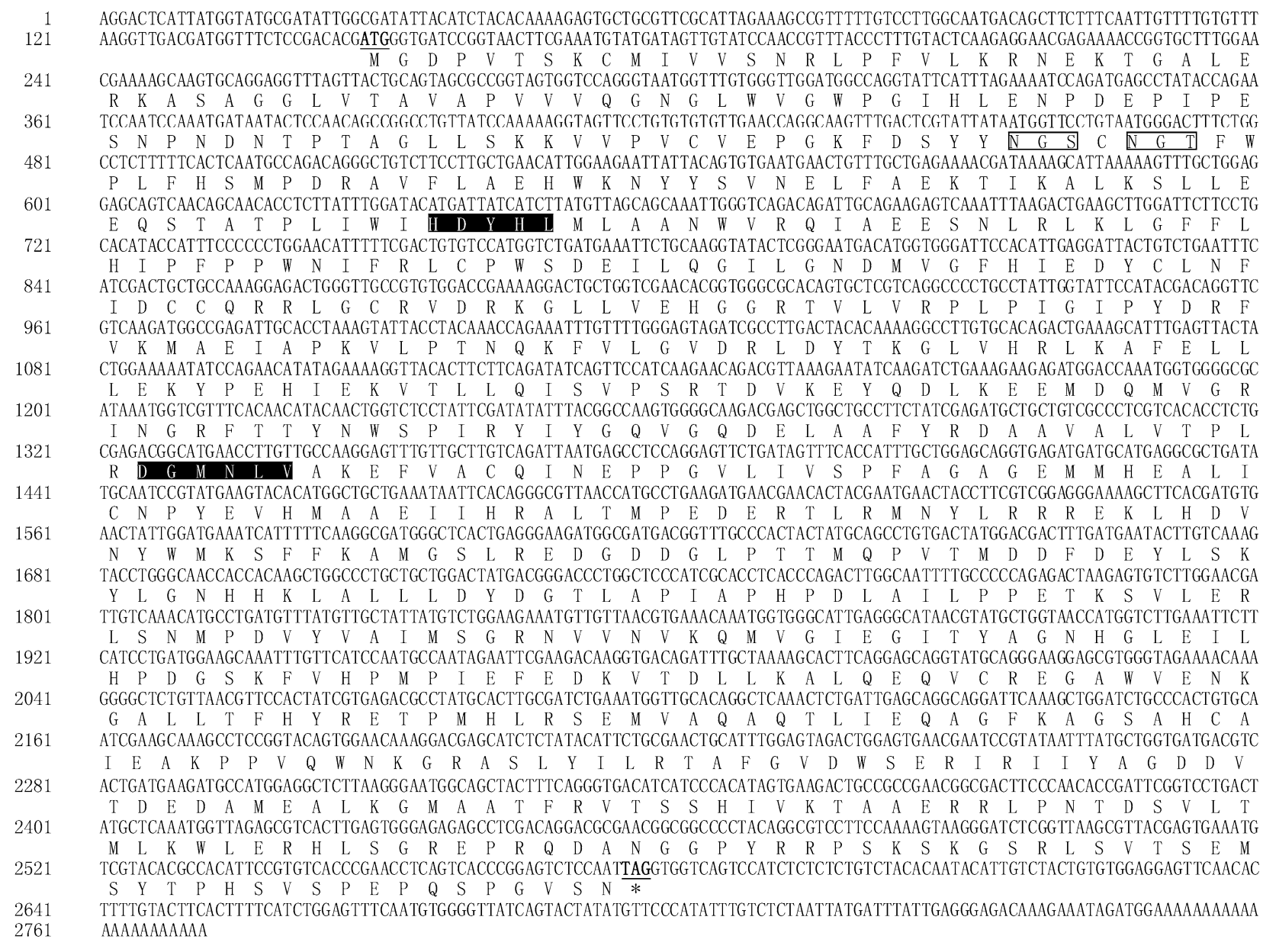

Fig. 1. Nucleotide and deduced amino acid sequences of CPiTPS. Underlined and bold nucleotides indicate the start and stop codons, respectively. Motifs (or signature motifs) unique to trehalose-6-phosphate synthase (TPS) (residues 163-167 and 393-398) are shaded in black. Potential N-glycosylation sites (residues 103-105 and 107-109) are boxed. The nucleotide sequence reported in this paper has been submitted to the GenBank database (accession no. GQ389790). The asterisk indicated the terminal protein.

\section{Rapid amplification of cDNA ends (RACE)}

For 5'- and 3'-RACE, cDNA was synthesized according to the manufacturer's protocol (BD SMART RACE cDNA Amplification Kit., Clontech of Takara, Dalian, China). Specific primers (CpiTPS-5R1/CpiTPS-5R2 for 5'-RACE and CpiTPS3F1/CpiTPS-3F2 for 3'-RACE; Table 1), were synthesized based on the cDNA sequence of the PCR fragment. 5'-RACE was performed using $2.5 \mu 1$ of 5 '-ready-cDNA with Universal Primer Mix (UPM, Clontech) and CpiTPS-5R1, then nested PCR was carried out with Nested Universal Primer A (NUP, Clontech) and CpiTPS-5R2. 3'-RACE was performed using 2.5 $\mu 1$ of 3 -ready-cDNA with UPM and CpiTPS-3F1, then with NUP and CpiTPS-3F2. The PCR conditions were as follows: 10 min at $94^{\circ} \mathrm{C}$, followed by 30 cycles of $30 \mathrm{~s}$ at $94^{\circ} \mathrm{C}, 30 \mathrm{~s}$ at $60^{\circ} \mathrm{C}$, and $80 \mathrm{~s}$ at $72^{\circ} \mathrm{C}$, then $10 \mathrm{~min}$ at $72^{\circ} \mathrm{C}$ (Wang et al., 2005a; Tang et al., 2010).

\section{Analysis of the CPiTPS cDNA sequence}

The CPiTPS cDNA sequence was compared with other TPS sequences deposited in the GenBank using the BLAST-N and BLAST-X tools on the National Center for Biotechnology Information (NCBI) website. The amino acid sequence of CpiTPS was deduced from the corresponding cDNA sequence using the translation tool on the ExPASy Proteomics website (http://expasy.org/tools/dna.html). A phylogenetic tree was constructed using MEGA 3.1 software based on the known TPS amino acid sequences. A bootstrap analysis was carried out and the robustness of each cluster was verified using 1000 replicates. Other protein sequence analysis tools used in this study, including molecular weight, $\mathrm{p} I$ and $\mathrm{N}$-glycosylation sites, were obtained from the ExPASy Proteomics website (http://expasy.org/). Multiple alignment of insect TPS sequences was performed using the tool on the multiple sequence alignment website http://bioinfo.genotoul.fr/multalin/multalin.html.

\section{Northern blot and RT-PCR analysis}

CpiTPS mRNA expression at different development stages and different seasons was determined by Northern blot and RT-PCR analysis. Total RNA was extracted from brain, trachea, midgut, rectum, testes, ovaries, Malpighian tubules, posterior extensor, heart, body wall, and fat body of young adults. Samples of $1 \mathrm{mg}$ of total RNA were reverse transcribed at $42^{\circ} \mathrm{C}$ for $1 \mathrm{~h}$ in a $10-\mu 1$ reaction solution containing reaction buffer, 10 $\mathrm{mM}$ DTT, $0.5 \mathrm{mM}$ dNTPs, $0.5 \mu \mathrm{g}$ of oligo-dT18, and 5 unit reverse transcriptase from avian myeloblastosis virus (AMV, Takara, Dalian, China). The product was used as the RT-PCR template. Another $25 \mathrm{mg}$ of total RNA was subsequently blotted onto a Hybond- $\mathrm{N}^{+}$membrane (Amersham of GE Healthcare, Little Chalfont Buckinghamshire, UK). Membranes were prehybridized at $42^{\circ} \mathrm{C}$ for $4 \mathrm{~h}$ and then incubated with the $\alpha{ }^{32} \mathrm{P}$ labelled CpiTPS probe (same probe as described for Southern blotting) at $42^{\circ} \mathrm{C}$ for $18 \mathrm{~h}$ in $5 \times$ SSPE containing $50 \%$ formamide, $5 \times$ Denhardt's solution, $0.1 \%$ SDS, and $100 \mathrm{mg} / \mathrm{ml}$ 


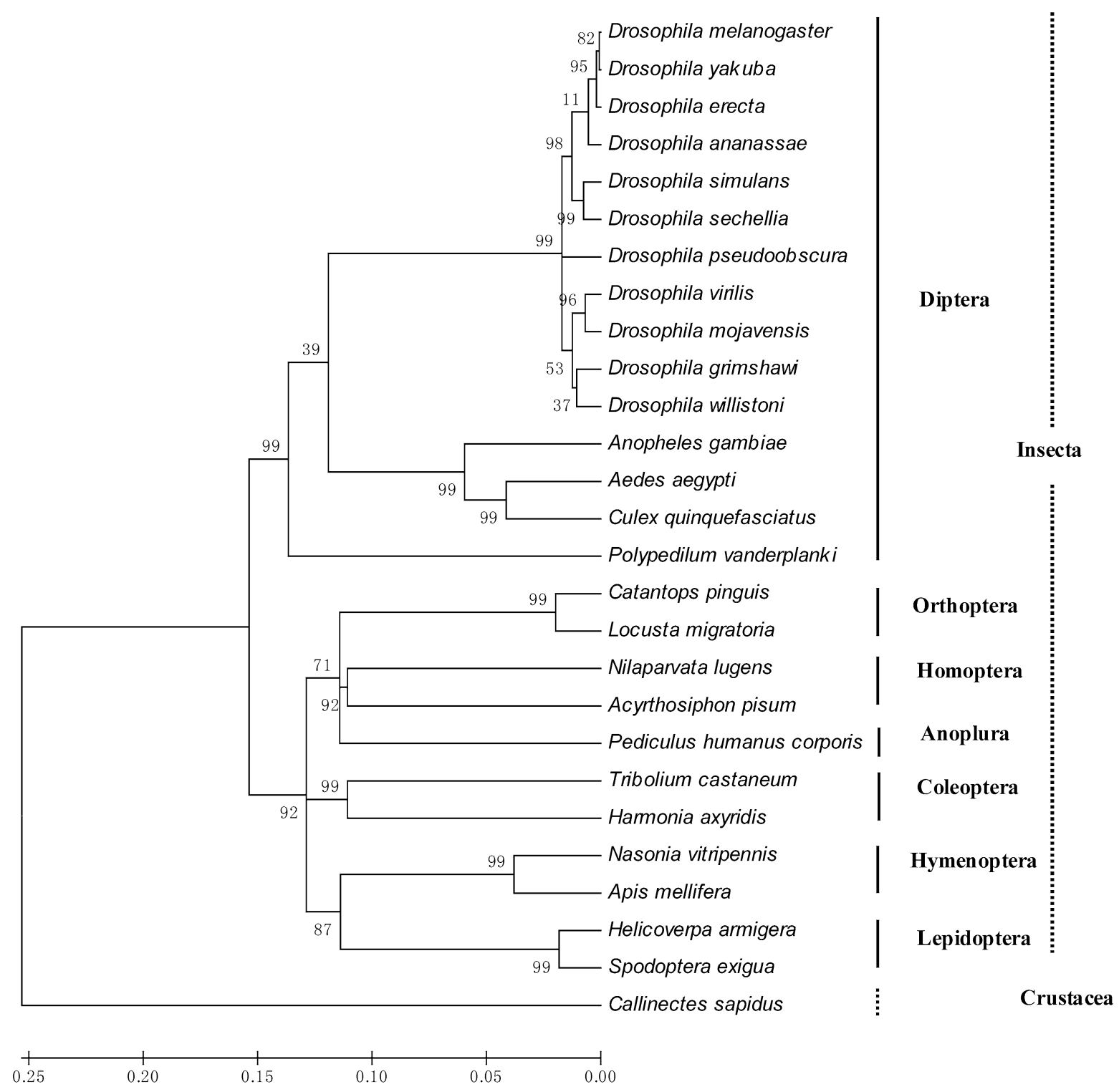

Fig. 2. Phylogenetic analysis of CpiTPS and TPS forms from other insect species. Phylogenetic tree was constructed based on amino acid sequences of known insect TPS forms and CpiTPS. Full-length amino acid sequences were aligned using the Mega 3.1 program to generate the phylogenetic tree. A bootstrap analysis was carried out and the robustness of each cluster was verified using 1000 replicates. Values at the cluster branches indicate the results of the bootstrap analysis. TPS forms were from Aedes aegypti (XM_001657763), Anopheles gambiae (XM_317243), Apis mellifera (XM_392397), Acyrthosiphon pisum (XM_001944186), Callinectes sapidus (EU679406), Culex quinquefasciatus (XM_001850946), C. pinguis (GQ389790), Drosophila erecta (XM 001968628), D. grimshawi (XM 001993159), D. melanogaster (NM 134983), D. mojavensis (XM 002003497), D. pseudoobscura (XM_001356952), D. sechellia (XM_002037774), D. virilis (XM_002059236), D. willistoni (XM_002066815), D. yakuba (XM_002087881), Harmonia axyridis (FJ501960), Helicoverpa armigera (EU878265), Locusta migratoria (EU131894), Nilaparvata lugens (GQ397450), Nasonia vitripennis (XM_001603643), Pediculus humanus corporis (XM_002433015), Polypedilum vanderplanki (AB490331), Spodoptera exigua (EF051258), and Tribolium castaneum (XM_970683).

salmon sperm DNA. After hybridization, the membrane was washed with $0.2 \times \mathrm{SSPE}$ at $45^{\circ} \mathrm{C}$, and exposed to X-ray film at $-70^{\circ} \mathrm{C}$ for $24 \mathrm{~h}$ (Choo et al., 2007; Tang et al., 2008).

RT-PCR was performed with the CpiTPS-FP/CpiTPS-RP primers. cDNA from brain, trachea, midgut, rectum, testes, ovaries, Malpighian tubules, posterior extensor, heart, body wall, and fat body was used as templates under the following conditions: 30 cycles of $40 \mathrm{~s}$ at $94^{\circ} \mathrm{C}, 40 \mathrm{~s}$ at $55^{\circ} \mathrm{C}$, and $60 \mathrm{~s}$ at $72^{\circ} \mathrm{C}$. Each PCR product $(5 \mu \mathrm{l})$ was subjected to electrophoresis and detected by ethidium bromide staining; the amount of $S$. exigua $\beta$-actin per lane was used as a loading control (Tang et al., 2008).

\section{RESULTS}

\section{Sequence analysis of CpiTPS cDNA}

CpiTPS cDNA (GenBank accession no. GQ389790) was obtained by PCR and $5^{\prime}-$ and $3^{\prime}$-RACE. CpiTPS cDNA has an open reading frame of 2430 nucleotides (Fig. 1), which encodes a protein of 809 amino acids with a predicted mass of approximately $91.13 \mathrm{kDa}$ and a $\mathrm{p} I$ value of 6.25 . CpiTPS is from $68-93 \%$ identical in structure to other known insect TPS forms (Fig. 2). 
121

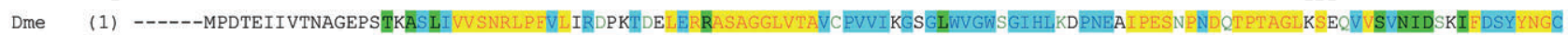

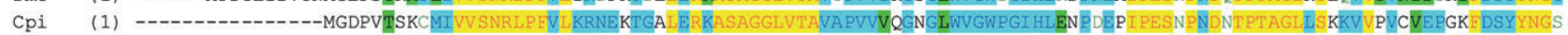

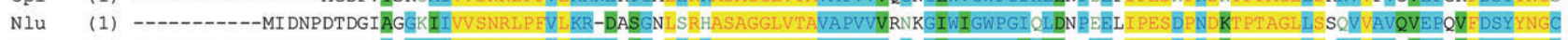
NVi (1) --------MTESRSYS-SNGSMIVV SNRLP FVLKRNETSGKLERKASAGGLVTAVAPVVINGWNGVWVGP GMHMENRNEPIPESDPND RTPTAGLLSRKVVAVHVEPTI EDSYYNGC

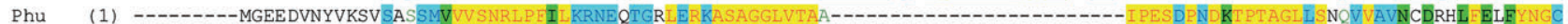

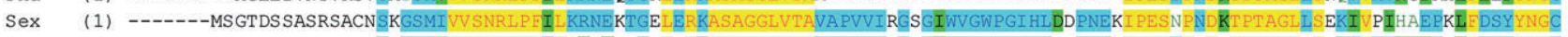

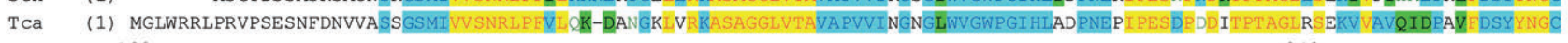
122 242

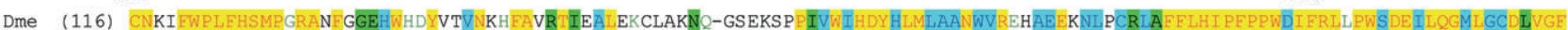

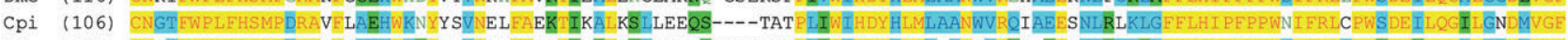

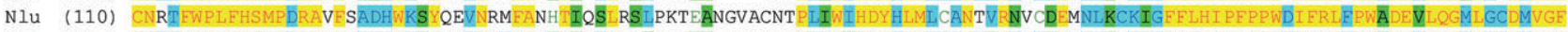

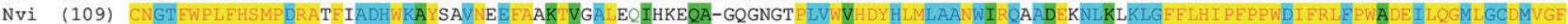

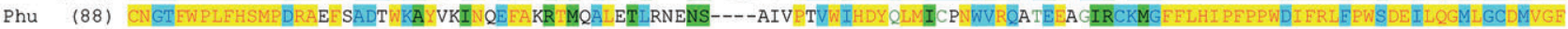

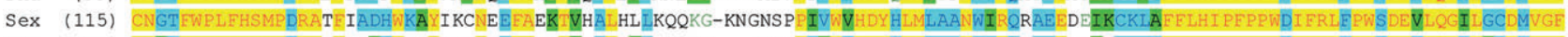

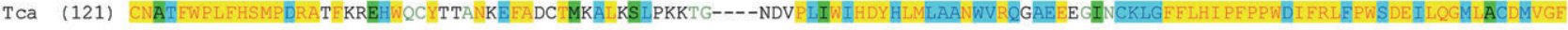
243 363

Dme (236) HIQDYCLNFVDCCQRNLGCRVDRNNLLVEHGGRTRVRPLPIGIPYERFVNLATTAPKVIKMS-KMQIILGVDRLDYTKGLVHRLMAFEALLLKYPQHKEKVSLLISVPSRTDVKEYREL

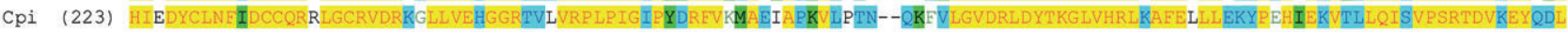
Nlu (231) HIEDYCLNFVDCCQRRLGCRVDRKGLLVEHGGRSVRVRPLPIGIPEDREVQLAESAPAVLAPAPAOKVVLGVDRLDYTKGLVHRLRAFEILLQKYPQHLEKVTLLISVPSRTDVKEYQEL NVi (229) HIQDYCLNFVDCCQRS LGCRVDRKNLLVEHGGRTVRVR LPIGIPFDREVSIAETAPKVMLTN--OKIILGVDRLDYTKGLVHRLKAFEMLLEKHPEHREVIMLQIAVPSRTDVREYQDI

Phu (205) HIEDYCLNFVDCCQRRLGCRVDRKNLLVEHGGRSVRRPLPIGIPEERFVIAESATRVMLTN--QQIVLGVDRLDYTKGLVHRLKAFERLLOKYPQHIEKVTLLQIAVPSRTDVREYQEL

Sex (235) HITDYCLNEIDCCQRNLGCRVDRKLLVELGGRTICVRPLPIGVPFDREVQLAQNÄKPVLSTN--QQVILGVDRLDYTKGLVHRLKAFERLLEKYPEHIEKVVLLQISVPSRTDVKEYQDL

Tca (238) HITDYCLNEVDCCQRNLGCRVDRKNLLVEHGGRSVRVRPLPIGIPFEREVELAEKAPRVLSTN--QRIVLGVDRLDYTKGLVHRLLAFEKLLENHPQHKEKVSLLISVPSRTDVKEYQDL 364 484

Dme (356) KEEVDQLVGINGRETTANWAPIRY IYDYVSQDELAALYRDAAVCLVTPLRD GMNLVAKE FVACQINEVPGVLVIS PFAGAGEMMHEALLCN PYEVNEAAEVIHRALTMPEDERVLRMARL

Cpi (342) KEEMDQMVGRINGRETTYNWSPIRYIYGQVGQDELAAFYRDAAVALVTPLRDGMNLVAKEFVACQINE PPGVLIVS PFAGAGEMMHEALICN PYEVHMAAEII HRALTMPEDERTLRMNYL

Nlu (352) KEEMDQLVGRINGRETTPNWSPIRYIYGCVSODELAAFYRDASVALVTPLRDGMNLVAKEFVACOINEPPGVLIVS PEAGAGEMMHEALICN PYEINDAAEVI HRALTMPEDERTLRMNYL

Nvi (348) KLEMDQLIGSINGRETTPNWSPIRYIYGCVS QDELAAFY RDAAVALVT PLRD GMNLVAKEFVACQINT TPPGVLIVS PEAGAGEMMHEALICN PYEIDEAAEVI HRALTMPEDERTLRMNH

Phu (324) KEEMDQLVGRINGCETTPNWSPIRYIYGCVSQDELAAFYRDAAVALVTPLRDGMNLVAKEFVACQINT TPGVLIVS PEAGAGEMMHEALVCN PYEIDDAAEVIHRALTMPEDERTLRMNYL

SeX (354) KEGMDQLVGRINGRETTPNWSPIRYIYGCVGQDELAAFYRDAAAALVTPLRDGMNLVAKEFVACQINKPPGVLIVS PEAGAGEMMHEALICN PYELDDAAEVIHRALIMPEDERTVRMNHL

Tca (357) KEEMDQLVGRINGKETTPNWSPIRYIYGCVS QDELAAFYRDAAVGLVTPLRDGMNLVAKEFVACQINT PPGVLIVSPFAGAGETMHEALICNPYEINDASEVIHRALTMPEDERIERMNYL 485 605

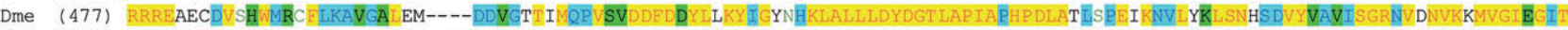
CDi (463) RRREKLHDVNYWMKSFFKAMGSIR--EDGDDGLPTTVOPVTMDDDEYISKYLCNHHKLALLLDYDTLAPIAPHPDLAILPPETKSVI ERLLSNMPDVYVAIMSGRNVVNVKOMVGIEGIT Nlu (473) RRREKTHNVDYWMS FLKAMGTLIS-EDGEEVLPTTMQPVTMD DFDEYSKYIGNTNKLALLLDYDGTLAPIAPHP DLAILPQETKHVLERL SNMP EVYISIISGRNVHNVKEMVGIDGLT Nvi (469) RRREKAY DVNHWMKS FLVVMGSIEER---DSVGATVMQPVTMD DEDDYISKYIGENHKLALLLDYDGTLAPIATHP DLATLPLETKNVLQRLSNLPDVYIAIISGRNVNNVKSMVGINGIT Phu (445) RRREKVHDVNYWMRS ELKAMGTLIT-EDGEETLPTTMQPVTLD DEDEYIAKYIGSSHKLALLLDYDGT LAPIAPHP DLAILPPETKNVLERLSNQS DVYIAIISGRNVENVKKMVGIKGIT Sex (475) RRREQINDVDS WMKAFLKAMDSIEEEA--DDIGATS SQPVTID DEDEYLSKYIGYTQKLALLLDYDGTLAPIAPHP DLATLPLETKHTLQRLSNMS DVYIAIISGRNV DNVKNMVGIEGIT

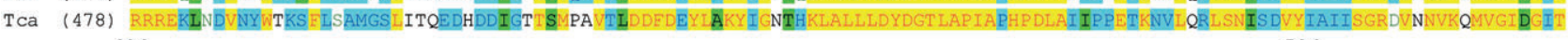
606

Dme (594) YAGNHGLEILHPDGSKEVHPMPMEYEKKVSDLLKALODSVCRDGAWVENKGALTTFHYRET PNHEGAMVDKARSLTEKYGFKATEAHCALEARPPVOWNKGRASIYYILRTSFCVDWNERI

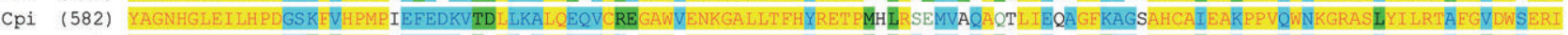
$\mathrm{Nlu}$ (593) YAGNHGLILHPDGSR MHPMPTEFEDKCSALLQALQEQVCKAGAWAENKGALLTEHYRET PIDVRREMVADARALIEAHGERAGEAHCALEAKRPVQWNKGRASIYYI LRTAFGLDWSERI Nvi (587) YAGNHGLEILHPDGSKFVHPMPAVEES KVAS LMOALODOLCKD GAWVENKGALLTEHYRET PMERRPSMIEHAKKLIEDAGFKACSAHCAIEAKPPVEWNKGRASIYI LRTAFGLDWSERI Phu (565) YAGNHGLILHPDGSKEVHPMPS SEEDKVTD LKALOEQVCKEGAWVENKGALLTEHYRETPLSLRPALVEQARQLIEAAGERAGRAHCAIEAKPPVQWNKGRASIYI LRTAEGVDWSERI Sex (594) YAGNHGLEILHPDGSKFVHPMPMËLDAVVVKLLKALQEQVCKDGAWVENKGALLTFHYRETPVAKRAALAEQARKLITEAGET PAPAHCALEARPPVEWDKGRASIYILRTAFGLDWSERI

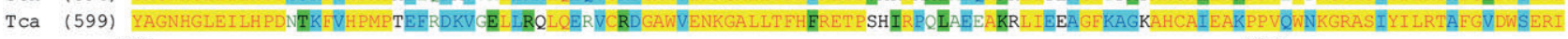

Dme (715) KIIYVGDDLTDEDAMVALKGMARTFRVTSSDIVKTA DHRLPSTDSVYTLLKWVERHEMGRKARANSTLTYR--------PTKGDGVQMUMSLEVAĀSANNLEV------------------

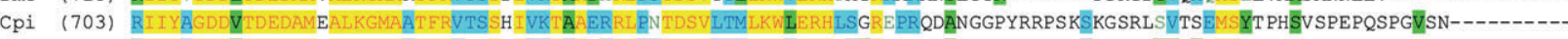

N1u (714) RIIYAGDDVTDEDAMEALKGMAATTFVAOSS IVKT SAQRRLPSTDSVLTMLKWVERHEKRAASGLÄSTQS---ASSSMRQQQALKIQMSLPSDTKR----------------------

Nvi (708) RIIYAGDDATDEDAMKALKGMAATERVASSHIIRTSAERRLPSTDSVLTMLKWVERHLSRRKPRNNNDVSS------KFRRGHSGITMEMSETQPSA--

Phu (686) RIIYÄGDTTDEDAMQALKGMAATFRITSSHIVKTAA EYYLPSTDSVLTMLKWVERHINRREEREPMHNEKRYHRSHS̈HLSNNGVTMEMSEDQDEKKSEKHNCEHIFTSNNAISIH--

Sex (715) RI IYAGDDVTDEDAMLALKGMAAT RRIASSNITKT SAERRLSSTDSVIAMLKWVERHESRRKPRANSLTYKK-----NÄRKARDTIQMHMSYQMPÄKTSPRHTPPLTPDKTSSGSESS

Tca (720) RIIYAGDDTTPEDAMQALKGMAATTFRVTSSS IVKT SAERRLPSTDSVLTMLKWVERHLSRRKPS IDPSNYR----RNS̈LAKQGAVQMEMSYTNTQQR-NGNSGRISTTDSTASH---

Fig. 3. Alignment of TPS proteins from insects. Alignment of TPS proteins from D. melanogaster (Dme), C. pinguis (Cpi), $N$. lugens (Nlu), N. vitripennis (Nvi), P. humanus corporis (Phu), S. exigua (Sex) and T. castaneum (Tc). GenBank accession numbers (DNA) are as follows: DmeTPS, NM 134983; CpiTPS, GQ389790; NluTPS, GQ397450; NviTPS, XM 001603643; PhuTPS, XM 002433015; SexTPS, EF051258; and TcTPS, XM 970683. The amino acid sequences deduced for insect TPS genes were aligned using Vector NTI 9.0 software. The fully conserved regions are shown in yellow and partly conserved regions in blue or green.

The deduced amino acid sequence of CpiTPS was aligned with TPS forms from other species, as shown in Fig. 2. CpiTPS is most similar to the TPS from Locusta migratoria (93\% identity). It is also similar to TPS forms from Apis mellifera (79\%), Nilaparvata lugens (76\%), Acyrthosiphon pisum (76\%), Pediculus humanus corporis (76\%), Tribolium castaneum (75\%), Harmonia axyridis (73\%), S. exigua (73\%), Anopheles gambiae (73\%), D. melanogaster (71\%), Aedes aegypti (71\%), Culex quinquefasciatus (71\%), Drosophila erecta (71\%), Drosophila grimshawi $(71 \%)$, Drosophila mojavensis $(71 \%)$, Drosophila pseudoobscura (71\%), Drosophila virilis
(71\%), Drosophila willistoni (71\%), Drosophila yakuba (71\%), Drosophila sechellia (69\%), and Polypedilum vanderplanki $(68 \%)$.

\section{Conserved sequence analysis of TPS}

Multiple sequence alignment of TPS proteins showed a high degree of conservation, particularly in the middle of the putative catalytic domain (Fig. 3). CpiTPS has two motifs (HDYHL and DGMNLV) that are conserved in TPS proteins, as well as many more conserved sequences, such as VVSNRLPF, ASAGGLVTA, FWPLFHSMP, FFLHIPFPPW, LGVDRLDYTKGLVHRL, LVTPLRDG 


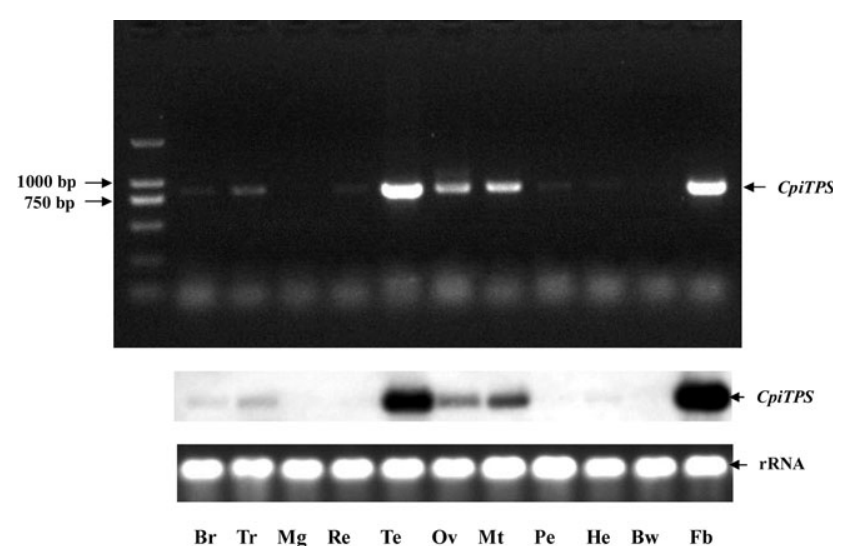

Fig. 4. RT-PCR (upper panel) and Northern blot (lower panel) analyses of CpiTPS transcripts in different tissues of adult Catantops pinguis. For Northern blot analysis, total RNA was extracted from various tissues: brain $(\mathrm{Br})$, trachea $(\mathrm{Tr})$, midgut $(\mathrm{Mg})$, rectum $(\mathrm{Re})$, testes $(\mathrm{Te})$, ovaries $(\mathrm{Ov})$, Malpighian tubules $(\mathrm{Mt})$, posterior extensor $(\mathrm{Pe})$, heart $(\mathrm{He})$, body wall $(\mathrm{Bw})$, and fat body $(\mathrm{Fb})$. A CPiTPS specific probe was radiolabelled with $\left[\alpha-{ }^{32} \mathrm{P}\right]-\mathrm{dCTP}$. Following hybridization and detection by autoradiography using the CPiTPS probes, membranes were stripped by boiling in $0.1 \%$ SDS. rRNA was used as a control.

\section{MNLVAKEFVACQIN, KLALLLDYDGTLAPIA, TYA GNHGLEILHPD, and ENKGALLTFH (Fig. 3).}

\section{Tissue distribution of CpiTPS}

Tissue-specific expression of CpiTPS was determined by Northern blotting and RT-PCR. CpiTPS transcripts were detected in fat body, testes, ovaries, Malpighian tubules, brain, trachea, rectum, and posterior extensor, but not in the mid-gut, heart or body wall of $C$. pinguis adults, which indicates that CpiTPS mRNA is expressed in many tissues of $C$. pinguis (Fig. 4). RT-PCR was performed to verify expression of CpiTPS mRNA in all of these tissues. PCR products of CpiTPS were consistent

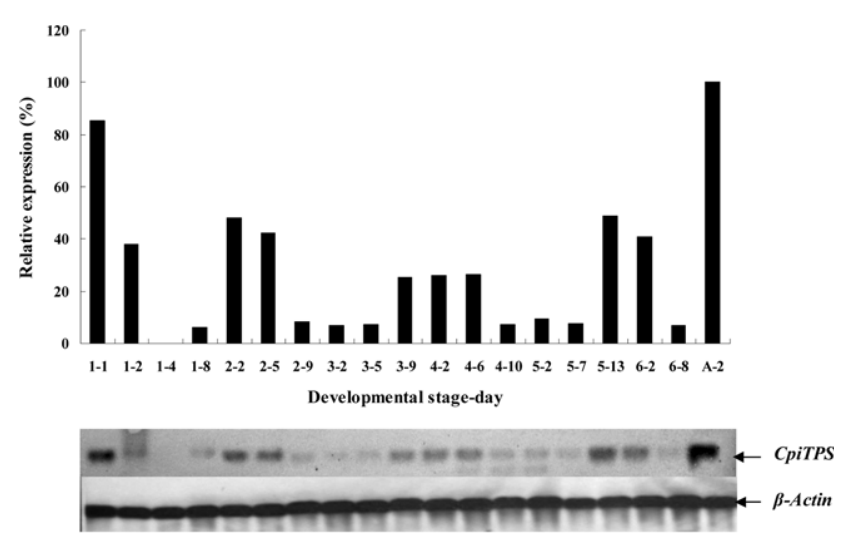

Fig. 5. Expression of CpiTPS mRNA in the fat body during the course of development. $\left[\alpha-{ }^{32} \mathrm{P}\right]$-dCTP-labelled CpiTPS cDNA, amplified using specific primers CpiTPS-FP and CpiTPS-RP, was used as a probe. $\beta$-actin was labelled with $\left[\alpha{ }^{32} \mathrm{P}\right] \mathrm{dCTP}$ as a control. RNA was extracted from fat body of different developmental stages, including first (1), second (2), third (3), fourth (4), fifth (5), and sixth instar larvae (6), and adults (A). The early, middle and late stages of each instar were assessed.
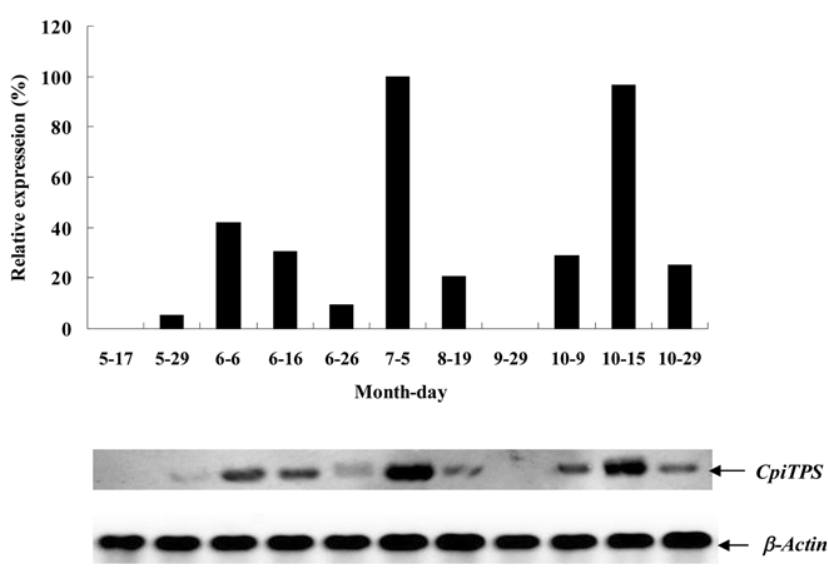

Fig. 6. Relative expression of CpiTPS mRNA in different seasons. RNA was extracted from fat body in different seasons from 17 May to 29 October. $\left[\alpha-{ }^{32} \mathrm{P}\right]$ dCTP-labelled CpiTPS cDNA, amplified using specific primers CpiTPS-FP and CpiTPS-RP, was used as a probe. $\beta$-actin was labelled with $\left[\alpha-{ }^{32} \mathrm{P}\right] \mathrm{dCTP}$ as a control.

with the Northern blot results, confirming that CpiTPS is specifically expressed in fat body, testes, ovaries, and Malpighian tubules.

\section{Expression of CpiTPS during development}

Northern blot experiments were carried out to analyze the expression patterns of CpiTPS in fat body during the development of $C$. pinguis from first instar larva to adult. The results showed that CpiTPS mRNA is expressed in the fat body at different levels at different developmental stages. CpiTPS transcripts were highly expressed in fat body in early first instar larvae, as well as in early and middle second instar larvae, late fifth instar larvae, and early sixth instar larvae and adults. Transcripts were present at a lower level in fat body of late first and second instar larvae, early, middle, and late third and fourth instar larvae, early and middle fifth instar larvae, and middle sixth instar larvae (Fig. 5). These results suggest that CpiTPS mRNA was expressed in the fat body according to the need of the different developmental stages, but most markedly in the egg to first instar larva and last instar larva to adult stages.

\section{Relative expression of CpiTPS in different seasons}

RT-PCR experiments to measure CpiTPS expression in adult fat body in different seasons of the year (from 17 May to 29 October) revealed that CpiTPS mRNA levels varied. CPiTPS transcripts were highly expressed in fat body in early July and mid-October. Transcripts were present at a lower level in fat body in early and mid-June, mid-August, and early and late October. Transcripts were hardly ever expressed in mid- and late May, and late June and September (Fig. 6). The results suggest that CpiTPS mRNA is expressed at varying levels in the fat body depending on developmental and behavioural requirements. 


\section{DISCUSSION}

It is reported that trehalose is exclusively synthesized by the fat body (Candy \& Kilby, 1959, 1961) from glucose phosphates and UTP. Many TPS genes have been cloned and reported from plants, yeast, and bacteria. An insect TPS gene was first cloned from D. melanogaster, encoding a protein of 809 amino acids and containing conserved domains similar to both yeast Tps1 (OtsA) and Tps2 (OtsB) (Chen et al., 2002). These authors, however, did not analyze the condition of the signature motifs or some protein characteristics. But there are two signature motifs (HDYHL and DGMNLV) according to the alignment of TPS protein sequences for insects, plants, bacteria, fungi, and nematodes. In $C$. pinguis, CpiTPS not only contains these signature motifs (Fig. 1), but also has other conserved motifs, such as VVSNRLPF, ASAGGLVTA, FWPLFHSMP, FFLHIPFPPW, LGVDRLDYTKGLV HRL, LVTPLRDGMNLVAKEFVACQIN, KLALLLDY DGTLAPIA, TYAGNHGLEILHPD, and ENKGALL TFH (Fig. 3).

TPS and TPP genes have been cloned from bacteria, fungi, and plants. In the genome of the plant Arabidopsis thaliana, there are 21 genes homologous to TPS that may have various functions (Leyman et al., 2001). In insects, the TPS gene was first cloned from $D$. melanogaster (Chen et al., 2002). Soon after, many TPS and TPP genes were cloned or deduced from genomic sequences, with two functional conserved domains similar to yeast genes, namely OtsA (TPS) and OtsB (TPP) (Chen et al., 2002; Chung 2008). According to the GenBank database, TPP genes have been identified in several insects, including $D$. melanogaster (BT100029), Maconellicoccus hirsutus (EF092085), Polypedilum vanderplanki (AB490334), C. quinquefasciatus (XM_001850944), A. aegypti (XM_001660971), and A. gambiae (XM_317247). Although TPS is a remarkably conserved gene family, Fig. 2 shows that TPS forms from Crustacea and Insecta can be clearly differentiated. Moreover, TPS forms from different insect species can also be differentiated.

It is reported that SexTPS is specifically expressed in the fat body and ovaries in larval stages, which is consistent with the results of studies on $H$. armigera (Xu et al., 2009, Tang et al., 2010). In Locusta migratoria, TPS is expressed not only in the fat body, but also in gut, hemolymph, and leg muscle (Cui \& Xia, 2009). However, in adult C. sapidus, CsaTPS is expressed in all tissues (Chung, 2008). In adult C. pinguis, TPS was not only expressed in fat body and ovaries, but also in the testes, Malpighian tubules, brain, trachea, rectum, and posterior extensor (Fig. 4). The distribution of CpiTPS in tissues is very similar to that of CsaTPS. These results suggest that the distribution of TPS in tissues may differ not only between larval and adult stages, but also among different arthropod species.

In non-diapausing and diapausing $H$. armigera, HarTPS mRNA expression was low and high, respectively (Xu et al., 2009). In addition, in S. exigua, semiquantitative RT-PCR results reveal that SexTPS mRNA is expressed in fat body at different levels from fifth instar larvae to pupae (Tang et al., 2010). Howerver, different patterns of expression of CpiTPS were found and studied (Fig. 5). The seasonal expression of CpiTPS from 17 May to 29 October was also investigated (Fig. 6). There are possibly two reasons for the variations in expression and lack of a regular pattern in different seasons. First, TPS expression is associated with development and behaviour. Second, TPS expression can be induced at particular times, just as TPS mRNA expression varies over the course of a day in nature.

In yeast, trehalose synthesis is mediated by a complex of TPS1 and TPS2. Trehalose has a dual function as a storage carbohydrate and a stress protection metabolite (Kwon et al., 2003; Thevelein, 1996). Transcriptional levels of TPS1 and TPS2 are increased by heat shock, cold or ethanol stress, salt stress, nutrient starvation, and other osmotic stresses (Winderickx et al., 1996; Wolschek \& Kubicek, 1997; Soto et al., 2002; Pereira et al., 2001). Improving stress tolerance is a major goal in agriculture. Over expression of TPS or TPP genes from either $E$. coil or yeast in tobacco, potato, and tomato improved drought tolerance, but only a limited accumulation of trehalose is recorded (Holmström et al., 1996; Romero et al., 1997; Yeo et al., 2000; Cortina CuliáñezMacià, 2005; Grennan, 2007). Miranda et al. (2007) report that transgenic Arabidopsis thaliana containing yeast TPS and TPP genes exhibited a significant increase in tolerance of drought, freezing, salt, and heat. Thus, a transgenic approach could be a potential tool for improving the stress tolerance of crops. Interestingly, the absence of TPS in Arabidopsis thaliana can result in the death of embryos (Eastmond et al., 2002; Gómez et al., 2006), demonstrating that AtTPS1 is essential for embryo development (Eastmond et al., 2002). In insects, particularly pests, suppressing the expression of the TPS gene inhibits development and may result in death. In D. melanogaster, a mutation in the TPS gene results in young larvae dying, which indicates that the TPS gene plays a critical role in insect development (Chen et al., 2002). SexTPS RNAi results also suggest that interference with TPS expression results in the death of larvae (Tang et al., 2010). Thus, TPS is a potential key gene that might also be used to control insect pests.

ACKNOWLEDGEMENTS. This work was supported by the National Natural Science Foundation of China (Grants IBN31000880 and 30970473), the Zhejiang Provincial Natural Science Foundation of China (Grants No. Y3100176 and Y307551), Hangzhou Science and Technology Development Program of China (Grants No. 20091133B08, 20081433B03, and 2006831 H09), Open-ended Foundation of State Key Lab for Biology of Plant Diseases and Insect Pests at Chinese Academy of Agriculture Sciences (Grant IBN-SKL2009OP17), Visiting Scholar Foundation of State Key Lab of Biocontrol at Sun Yat-sen University (Grant IBN-SKLBC09F03), National Basic Research Program of China (Grants IBN-2009CB119206 and 2006CB 102005-3) and the Hangzhou normal university high-level talents start-up fund (Grant No. YS05203105). 


\section{REFERENCES}

Avonce N., Mendoza-Vargas A., Morett E. \& Iturriaga G. 2006: Insights on the evolution of trehalose biosynthesis. BMC Evol. Biol. 6: 109.

Becker A., Schloder P., Steele J.E. \& Wegener G. 1996: The regulation of trehalose metabolism in insects. Experientia 52: 433-439.

Benaroudj N., Lee D. \& Goldberg A. 2001: Trehalose accumulation during cellular stress protects cells and cellular proteins from damage by oxygen radicals. J. Biol. Chem. 276: 24261-24267.

Birch G.G., Wolfrom M.L. \& Tyson R.S. 1963: Adv. Carbohydr. Chem. Academic Press, New York, pp. 201-225.

CABIB E. \& Leloir L.F. 1958: The biosynthesis of trehalose phosphate. J. Biol. Chem. 231: 259-275.

Candy D.J. \& Kilby B.A. 1959: Site and mode of trehalose biosynthesis in the locust. Nature 183: 1594-1595.

CANDY D.J. \& Kilby B.A. 1961: The biosynthesis of trehalose in the locust fat body. Biochem. J. 78: 531-536.

CHen Q. \& HADDAD G.G. 2004: Role of trehalose phosphate synthase and trehalose during hypoxia: from flies to mammals. J. Exp. Biol. 207: 3125-3129.

Chen Q., Ma E., Behar K., Xu T. \& Haddad G.G. 2002: Role of trehalose phosphate synthase in anoxia tolerance and development in Drosophila melanogaster. J. Biol. Chem. 277: 3274-3279.

Chen Q., Behar K., Xu T., Fan C. \& Haddad G.G. 2003: Expression of Drosophila trehalose-phosphate synthase in HEK-293 cells increases hypoxia tolerance. J. Biol. Chem. 278: 49113-49118.

Chomczynski P. \& SAcchi N. 1987: Single-step method of RNA isolation by acid guanidinium thiocyanate-phenol-chloroform extraction. Anal. Biochem. 162: 156-159.

Choo Y.M. Lee K.S., Kim B.Y., Kim D.H., Yoon H.J., Sohn H.D. \& JIN B.R. 2007: A gut-specific chitinase from the mulberry longicorn beetle, Apriona germari (Coleoptera: Cerambycidae): cDNA cloning, gene structure, expression and enzymatic activity. Eur. J. Entomol. 104: 173-180.

Chung J.S. 2008: A trehalose 6-phosphate synthase gene of the hemocytes of the blue crab, Callinectes sapidus: cloning, the expression, its enzyme activity and relationship to hemolymph trehalose levels. Saline Syst. 4: 18.

Cortina C. \& Culiáñez-Macià FA. 2005: Tomato abiotic stress enhanced tolerance by trehalose biosynthesis. Plant Sci. 169: 75-82.

Crowe J.H., Crowe L.M. \& Chapman D. 1984: Preservation of membranes in anhydrobiotic organisms: the role of trehalose. Science 223: 701-703.

Cui S.Y. \& XIA Y.X. 2009: Isolation and characterization of the trehalose-6-phosphate synthase gene from Locusta migratoria manilensis. Insect Sci. 16: 287-295

Eastmond P.J., Van Dijken A.J., Spielman M., Kerr A., Tissier A.F., Dickinson H.G., Jones J.D., Smeekens S.C. \& Graham I.A. 2002: Trehalose-6-phosphate synthase 1, which catalyses the first step in trehalose synthesis, is essential for Arabidopsis embryo maturation. Plant J. 29: 225-235.

Elbein A.B. 1974: The metabolism of $\alpha, \alpha$-trehalose. Adv. Carbohydr. Chem. Biochem. 30: 227-256.

Elbein A.D., Pan Y.T., Pastuszak I. \& Carroll D. 2003: New insights on trehalose: a multifunctional molecule. Glycobiology 13: 17R-27R.

Fillinger S., Chaveroche M., Van Dijck P., de Vries R., Ruijter G., Thevelein J. \& D'Enfert C. 2001: Trehalose is required for the acquisition of tolerance to a variety of stresses in the filamentous fungus Aspergillus nidulans. Microbiology 147: 1851-1862.

Gadd G.M., Chalmers K. \& Reed R.H. 1987: The role of trehalose in dehydration resistance of Saccharomyces cerevisiae. FEMS Microbiol. Lett. 48: 249-254.

Garg A., Kim J., Owens T., Ranwala A., Choi Y., Kochian L. \& Wu R.J. 2002: Trehalose accumulation in rice plants confers high tolerance levels to different abiotic stresses. Proc. Natl. Acad. Sci. U.S.A. 99: 15898-15903.

Gómez L.D., Baud S., Gilday A., Li Y. \& Graham I.A. 2006: Delayed embryo development in the Arabidopsis Trehalose6-phosphate Synthase 1 mutant is associated with altered cell wall structure, decreased cell division and starch accumulation. Plant J. 46: 69-84.

Grennan A. 2007: The role of trehalose biosynthesis in plants. Plant Physiol. 144: 3-5.

Holmström K.O., Mäntylä E., Welin B., Mandal A., Palva E.T., Tunnela O.E. \& Londesborough J. 1996: Drought tolerance in tabacco. Nature 379: 683-684.

JAng I., Oh S., Seo J., Choi W., Song S., Kim C., Kim Y., Seo H., Choi Y., NAhм B. \& KIM J.K. 2003: Expression of a bifunctional fusion of the Escherichia coli genes for trehalose-6phosphate synthase and trehalose-6-phosphate phosphatase in transgenic rice plants increases trehalose accumulation and abiotic stress tolerance without stunting growth. Plant Physiol. 131: 516-524.

Kizawa H., Miyagawa K. \& Styvold O.B. 1995: Purification and characterization to trehalose phosphorylass from Micrococcus varians. Biosci. Biotech. Biochem. 59: 1908-1912.

Kong X.D., Liu Y., Gou X.J., Zhang H.Y., Wang X.P. \& Zhang J. 2001: Directed evolution of operon of trehalose-6phosphate synthase/phosphatase from Escherichia coli. Biochem. Bioph. Res. Commun. 280: 396-400.

Kumar N.S., Tang B., Chen X.F., Tian H.G. \& Zhang W.Q. 2008: Molecular cloning, expression and structure of chitin synthase gene B in Spodoptera exigua. Comp. Biochem. Physiol. (B) 149: 447-453.

Kwon H.B., Yeo E.T., Hahn S.E., Bae S.C., Kim D.Y. \& Byun M.O. 2003: Cloning and characterization of genes encoding trehalose-6-phosphate synthase (TPS1) and trehalose-6phosphate phosphatase (TPS2) from Zygosaccharomyces rouxii. FEMS Yeast Res. 3: 433-440.

Leyman B., VAN Dijck P. \& Thevelein J. 2001: An unexpected plethora of trehalose biosynthesis genes in Arabidopsis thaliana. Trends Plant Sci. 6: 510-513.

Madigan M.T. \& Oren A. 1999: Thermophilic and halophilic extremophiles. Curr. Opin. Microbiol. 2: 265-269.

Miranda J., Avonce N., Suárez R., Thevelein J., Van Dijck P. \& IturRiaga G. 2007: A bifunctional TPS-TPP enzyme from yeast confers tolerance to multiple and extreme abiotic-stress conditions in transgenic Arabidopsis. Planta 226: 1411-1421.

Noguchi H. \& Hayakawa Y. 2001: Dopamine is a key factor for the induction of egg diapause of the silkworm, Bombyx mori. Eur. J. Biochem. 268: 774-780.

Pereira M., Eleutherio E. \& Panek A. 2001: Acquisition of tolerance against oxidative damage in Saccharomyces cerevisiae. BMC Microbiol. 1: 11.

Rinehart J.P., Diakoff S.J. \& Denlinger D.L. 2003: Sarcotoxin II from the flesh fly Sarcophaga crassipalpis (Diptera): A comparison of transcript expression in diapausing and nondiapausing pupae. Eur. J. Entomol. 100: 251-254.

Romero C., Belles J.M., Vaya J.L., Serrano R. \& CuliañezMaCiÀ F.A. 1997: Expression of the yeast trehalose-6phosphate synthase gene in transgenic tobacco plants: 
pleiotropic phenotypes include drought tolerance. Planta 201: 293-297.

Ryu S., Park C., Cha J., Woo E. \& Lee S.B. 2005: A novel trehalose-synthesizing glycosyltransferase from Pyrococcus horikoshii: molecular cloning and characterization. Biochem. Bioph. Res. Commun. 329: 429-436.

Soto T., Beltrán F., Paredes V., Madrid M., Millar J., Vicente-Soler J., Cansado J. \& Gacto M. 2002: Cold induces stress-activated protein kinase-mediated response in the fission yeast Schizosaccharomyces pombe. Eur. J. Biochem. 269: 5056-5065.

StRøM A.R. \& KAASEN I. 1993: Trehalose metabolism in Escherichia coli: stress protection and stress regulation of gene expression. Mol. Microbiol. 8: 205-210.

Tang B., Chen X.F., Liu Y., Tian H.G., Liu J., Hu J., Xu W.H. \& ZHANG W.Q. 2008: Characterization and expression patterns of a membrane-bound trehalase from Spodoptera exigua. BMC Mol. Biol. 9: 51.

Tang B., Chen J., Yao Q., Pan Z.Q., Xu W.H., Wang S.G. \& ZHANG W.Q. 2010: Characterization of a trehalose-6phosphate synthase gene from Spodoptera exigua and its function identification through RNA interference. $J$. Insect Physiol. 56: 813-821.

TheVELEIN J.M. 1996: Regulation of trehalose metabolism and its relevance to cell growth and function. In Brambl R. \& Marzluf G.A. (eds): The Mycota. Springer, Berlin, pp. 395-420.

Tsusaki K., Nishimoto T., Nakada T., Kubota M., Chaen H., Fukuda S., Sugimoto T. \& Kurimoto M. 1997: Cloning and sequencing of trehalose synthase gene from Thermus aquaticus ATCC33923. Biochim 1334: 28-32.
Wang Y., Hao Y., Zhang Z., Chen T., Zhang J. \& Chen S. 2005a: Isolation of trehalose-6-phosphate phosphatase gene from tobacco and its functional analysis in yeast cells. $J$. Plant Physiol. 162: 215-223.

WANG G.R., Liang G.M., Wu K.M. \& Guo Y.Y. 2005b: Gene cloning and sequencing of aminopeptidase N3, a putative receptor for Bacillus thuringiensis insecticidal Cry1Ac toxin in Helicoverpa armigera (Lepidoptera: Noctuidae). Eur. J. Entomol. 102: 13-19.

Winderickx J., de Winde J., Crauwels M., Hino A., Hohmann S., Van Dijck P. \& Thevelein J. 1996: Regulation of genes encoding subunits of the trehalose synthase complex in Saccharomyces cerevisiae: novel variations of STRE-mediated transcription control? Mol. Gen. Genet. 252: 470-482.

WolscheK M. \& KUBiceK C. 1997: The filamentous fungus Aspergillus niger contains two "differentially regulated" trehalose-6-phosphate synthase-encoding genes, tpsA and tpsB. J. Biol. Chem. 272: 2729-2735.

Xu J., Bao B., Zhang Z.F., YI Y.Z. \& Xu W.H. 2009: Identification of a novel gene encoding the trehalose phosphate synthase in the cotton bollworm, Helicoverpa armigera. Glycobiology 19: 250-257.

Yancey P.H., Clark M.E., Hand S.C., Bowlus R.D. \& Somero G.N. 1982: Living with water stress: evolution of osmolyte systems. Science 217: 1214-1222.

Yeo E.T., Kwon H.B., Han S.E., Lee J.T., Ryu J.C. \& Byun M.O. 2000: Genetic engineering of drought resistant potato plants by introduction of the trehalose-6-phosphate synthase (TPS1) gene from Saccharomyces cerevisiae. Mol. Cell 10: 263-268.

Received June 10, 2010; revised and accepted January 7, 2011 